\section{Delayed perforation 10 days after endoscopic hemostasis using hemostatic forceps for a bleeding Dieulafoy lesion}

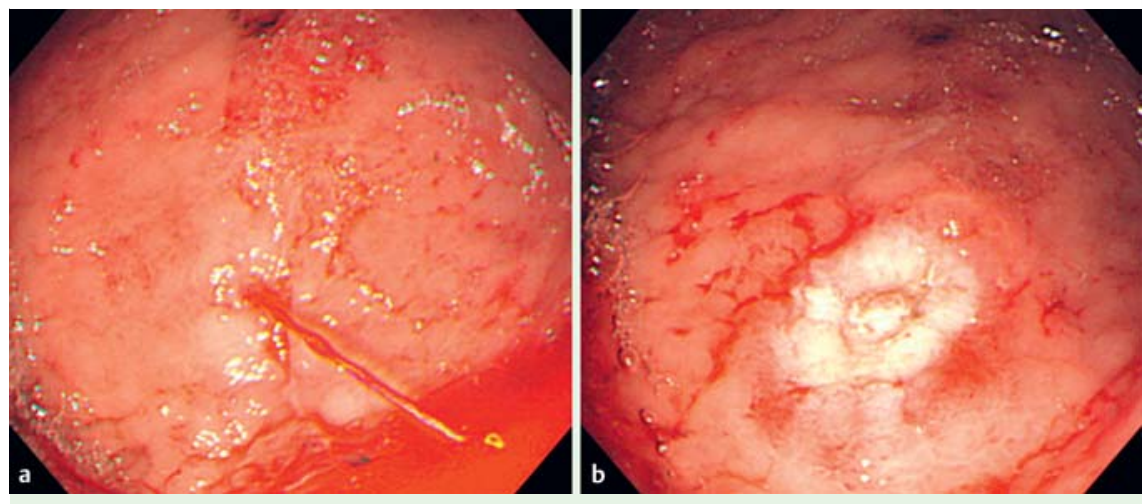

Fig. 1 Emergent endoscopic examination after hematemesis in an 83-year-old man who had undergone treatment for early gastric cancer. a Dieulafoy lesion is located at the greater curvature of the gastric remnant with arterial bleeding. $\mathbf{b}$ The bleeding point was coagulated with hemostatic forceps using the soft coagulation mode at $80 \mathrm{~W}$.
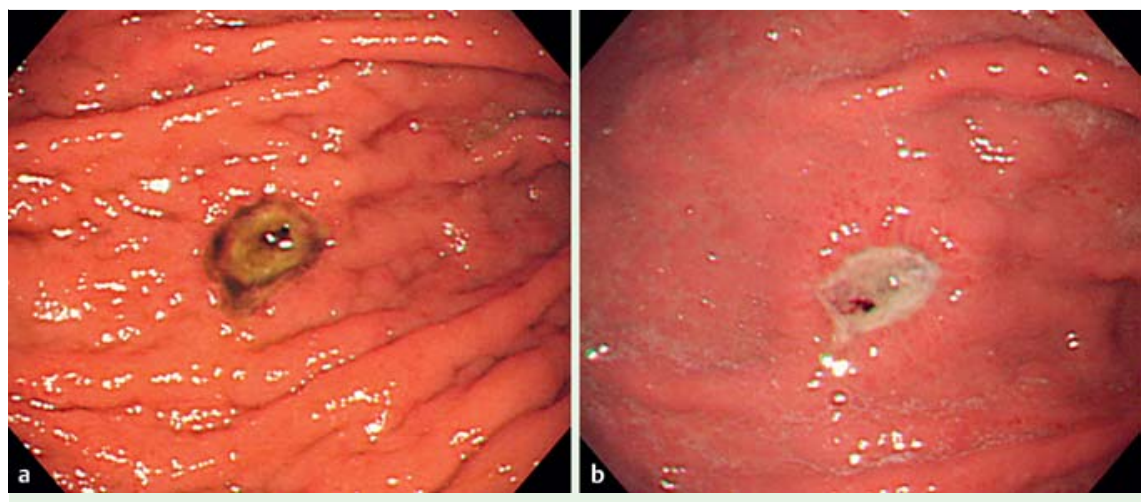

Fig. 2 Follow-up endoscopic view showing absence of delayed bleeding and perforation at the hemostatic site on days 3 (a) and 7 (b) post hemostasis.


Fig.3 Emergent endoscopy 10 days after hemostasis. a A 3-mm perforation is visible in the hemostatic ulcer (arrow). b The perforation closed with nine endoclips.
To our knowledge, there have been no reports in the English literature of cases of delayed perforation occurring more than 2 days after hemostasis for gastrointestinal bleeding, including bleeding related to endoscopic submucosal dissection. Additionally, according to previous reports $[1,2]$, in patients with delayed perforation, surgery was often required to improve their clinical course. We report a rare case of successful conservative treatment for delayed perforation occurring 10 days after endoscopic hemostasis using hemostatic forceps for a bleeding Dieulafoy lesion.

An 83-year-old man was admitted to our hospital for the treatment of early gastric cancer. The patient underwent pyloruspreserving gastrectomy and lymph node dissection. On postoperative day 26 , he had massive hematemesis. Emergent endoscopy showed a bleeding Dieulafoy lesion at the greater curvature of the gastric remnant ( $\bullet$ Fig. 1 a). The bleeding point was grasped and coagulated with hemostatic forceps (Coagrasper, FD-410LR; Olympus, Tokyo, Japan), using the soft coagulation mode at $80 \mathrm{~W}(\bullet$ Fig. $\mathbf{1 b}$ ). Follow-up endoscopic examinations showed no evidence of delayed bleeding at the hemostatic site on days 3 and 7 after the hemostasis procedure ( $\bullet$ Fig. 2 ). However, on day 10 after hemostasis, the patient complained of severe upper abdominal pain. Free air and ascites were seen in the peritoneal cavity on emergent computed tomography and endoscopic examination revealed a perforation of $3 \mathrm{~mm}$ in diameter in the hemostatic ulcer ( $\bullet$ Fig. $\mathbf{3 a}$ ). The perforation was closed endoscopically with nine endoclips (HX-600-090L; Olympus) ( Fig.3b). The general condition of the patient as well as the laboratory data and radiographic findings gradually improved, and 40 days after the perforation he was discharged.

Endoscopy_UCTN_Code_CPL_1AH_2AC

Competing interests: None

\section{S. Ninomiya ${ }^{1}$, H. Shiroshita ${ }^{1}$, T. Bandoh ${ }^{1}$, W. Soma ${ }^{2}$, H. Abe ${ }^{2}$, T. Arita ${ }^{1}$}

${ }^{1}$ Department of Surgery, Arita Gastrointestinal Hospital, Oita, Japan

2 Department of Internal Medicine, Arita Gastrointestinal Hospital, Oita, Japan 


\section{References}

1 Hanaoka $N$, Uedo $N$, Ishihara $R$ et al. Clinical features and outcomes of delayed perforation after endoscopic submucosal dissection for early gastric cancer. Endoscopy 2010; 42: $1112-1115$

2 Ikezawa K, Michida T, Iwahashi $K$ et al. Delayed perforation occurring after endoscopic submucosal dissection for early gastric cancer. Gastric Cancer 2012; 15: 111 114
Bibliography

Dol http://dx.doi.org/

10.1055/s-0032-1326275

Endoscopy 2013; 45: E99-E100

(c) Georg Thieme Verlag KG

Stuttgart · New York

ISSN 0013-726X
Corresponding author

\section{S. Ninomiya}

Department of Surgery

Arita Gastrointestinal Hospital

Maki 1-2-6

Oita 870-0924

Japan

Fax: +81-97-5561778

sninomiy@med.oita-u.ac.jp 